\title{
Contralateral neck dissection in oral squamous cell carcinoma: when it should be done?
}

\section{Laura Villanueva-Alcojol}

Department of Oral and Maxillofacial-Head and Neck Surgery, University Hospital Infanta Cristina, 06080 Badajoz, Spain. Correspondence Author: Dr. Laura Villanueva-Alcojol, Department of Oral and Maxillofacial Surgery, University Hospital Infanta Cristina, Avenida de elvas s/n, 06080 Badajoz, Spain. E-mail: lauravillanueva@hotmail.com

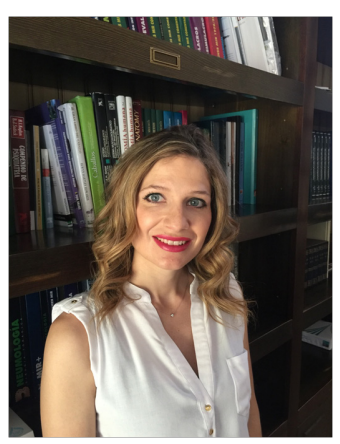

Dr. Laura Villanueva-Alcojol, M.D., Ph.D., obtained her Medical Degree at University of Extremadura School of Medicine in Badajoz, Spain, in 2006. She received in 2012 her speciality in Oral and Maxillofacial Surgery at the University Hospital Infanta Cristina, Badajoz, Spain. She has been working as a consultant at the Department of Oral and Maxillofacial Surgery in University Hospital Infanta Cristina, Badajoz, Spain, since then. She obtained her Doctoral Thesis about "Characteristics of newly formed bone after sinus lift procedures: analysis with micro-CT, histology and Cone-Beam CT" in 2013 at the University of Extremadura School of Medicine, Badajoz, Spain. Actually, she is University Honorary Collaborator at the University of Extremadura School of Medicine, Badajoz, Spain.

\begin{abstract}
Oral cavity squamous cell carcinoma (OSCC) has a high incidence of cervical micrometastases and sometimes metastasizes bilaterally because of the rich lymphatics in the submucosal plexus, which freely communicate across the midline. The presence of contralateral pathologic lymph nodes has been reported previously as a critical factor influencing the survival of patients. There are a few reports in the literature with regard to the rates of contralateral neck disease and the factors that may be involved in the risk with them. An elective ipsilateral neck treatment is generally recommended for initial treatment in all OSCC. However, no consensus exists whether or not to perform an elective contralateral neck dissection or radiation. In this study, a systematic review has been performed in order to evaluate the predictive value of clinical-histopathologic factors potentially related to contralateral occult lymph node metastasis in squamous cell carcinomas of the oral cavity to form a rational basis for elective contralateral neck management.
\end{abstract}

Key words:

Contralateral neck dissection; squamous cell carcinoma; oral cavity; oral cancer

\section{INTRODUCTION}

Head and neck cancer is the fifth most common type of cancer worldwide, among all neoplasms. Approximately

\begin{tabular}{|l|l|}
\hline \multicolumn{2}{|c|}{ Access this article online } \\
\hline Quick Response Code: & Website: \\
\hline & http://www.parjournal.net \\
\cline { 2 - 3 } & \\
\hline
\end{tabular}

$40 \%$ of them occur in the oral cavity. Squamous cell carcinoma (SCC) is the most common histological type, with a frequency of approximately $90 \%$. The presence

This is an open access article distributed under the terms of the Creative Commons Attribution-NonCommercial-ShareAlike 3.0 License, which allows others to remix, tweak and build upon the work non-commercially, as long as the author is credited and the new creations are licensed under the identical terms.

For reprints contact: service@oaepublish.com

How to cite this article: Villanueva-Alcojol L. Contralateral neck dissection in oral squamous cell carcinoma: when it should be done? Plast Aesthet Res 2016;3:181-8.

Received: 30-03-2016; Accepted: 08-06-2016 
of neck lymph node metastasis is the most significant prognostic and survival factor in patients with oral cavity squamous cell carcinoma (OSCC). With the exception of thin early-stage tumours in the context of clinically and radiologically node negative necks, most patients with OSCC undergo neck dissection. ${ }^{[1]}$ This has the benefit of treating occult metastatic disease and providing pathological staging information to direct adjuvant therapy. ${ }^{[2,3]}$ The rich lymphatic connections in the head and neck makes oral cavity malignancies susceptible to spread across the midline. ${ }^{[4]}$ The SCC of the oral cavity presents a variable frequency of contralateral lymph neck metastases (CLNM) between $0.9 \%$ to $36 \%$, reported in the literature. ${ }^{[5,6]}$ The presence of such metastases decreases the survival rate of the patients, generating a poor prognosis. ${ }^{[7]}$ Although elective treatment of the contralateral neck is accepted for OSCC approaching or crossing the midline, this is not routinely performed in lateralized cases. Few studies have analyzed rates of contralateralneck disease in oral cancer and thefactors that may be involved with them. In terms of treatment decision-making, the use of elective contralateral neck dissection remains controversial for patients with OSCC that does not cross the midline.

The purpose of this review was to evaluate the incidence of CLNM and analyze the factors that may predict their appearance in OSCC to form a rational basis for elective contralateral neck management.

\section{METHODS}

To address the research purpose, the authors designed and implemented a systematic review of the literature. The electronic search was perfomed in the Cochrane Library, MEDLINE via Pubmed and EMBASE using the key terms "contralateral neck dissection", "contralateral metastases", "oral squamous cell carcinoma" and "oral cancer". Some of these terms were searched in combination. The references of each article obtained were checked for additional relevant studies. Only articles published in English were included in this study. One reviewer screened all titles and abstracts. A total of 103 references were retrieved, of which 34 were screened. The exclusion criteria were: (1) date of publication before 1999; (2) articles written in a language different from English; (3) required data not available; and (4) type of article: abstracts, letters, comments, editorials, expert opinions or case reports.

\section{THE ROLE OF CLNM IN OSCC}

The contralateral metastasis propagation can occur in the head and neck carcinoma in different ways: firstly, by crossing afferent lymphatic vessels, by tumor spread along the midline, when ipsilateral lymph nodes are widely involved, and secondly, in certain anatomical areas where there is not a real barrier in the midline. ${ }^{[7]}$
The OSCC has a high incidence of micrometastases and often bilaterally metastases due to the rich submucosal lymphatic plexus, that communicates freely crossing the middle line..$^{|8|}$ It presents a variable incidence of CLNM between $0.9 \%$ to $36 \%$, reported in the literature. Diverse factors can be held responsible for such differences, among them the diversity of the anatomic regions considered for study, problems in clinical staging, and exclusion of cases not considered eligible for treatment. Kowalski et al. ${ }^{[6]}$ found a rate of $36 \%$ of contralateral positive nodes after bilateral neck dissection. Kurita et $a l .^{[5]}$ observed an incidence of CLNM in early oral tongue SCC of $12.2 \%$. In the paper reported by Koo et al. ${ }^{|8|}$ the overall rate of occult contralateral metastasis in OSCC was $11 \%$, and the rate was $21 \%$ in cases of ipsilateral pathologic metastasis. In the study of Bier Laning et al..$^{|9|}$ the incidence was $10 \%$. This corresponds to the findings of Mukherji et al. ${ }^{[10]}$ who found that oral tongue and floor-of-mouth cancers had an expected drainage to contralateral lymph nodes in up to $9 \%$ of cases. On the other hand, Lim et al ${ }^{[11]}$ in their study detected only a $4 \%$ rate of contralateral occult metastases in a series of early tongue carcinomas and did not recommend elective contralateral neck treatment. González-García et al. ${ }^{[12]}$ in a large series of 315 patients with oral squamous cell carcinoma of the oral cavity, reported an incidence rate of $5.7 \%$ for CLNM, which is similar to the 5-year CLNM rate of $4.1 \%$ reported by Feng et al. ${ }^{[13]}$ while another large cohort study by Huang et al. ${ }^{[14]}$ showed a 7.1\% 5-year CLNM rate.

In relation to prognosis, it has been widely accepted that CLNM dramatically reduce the long-term survival and prognosis in these patients is described as extremely poor. ${ }^{[6,8,15,16]}$ Capote-Moreno et al. ${ }^{[7]}$ reported a decrease in the 5-year survival rate in patients with OSCC, from $70 \%$ in patients with negative contralateral lymph nodes to $41.2 \%$ in those with CLNM. These rates were similar to those found by other authors; for example, Koo et al. ${ }^{[8]}$ found a 5-year cause-specific survival rate of $43 \%$ in patients with contralateral disease compared with $73 \%$ in metastasis-free patients in a series of 173 cases with oral and oropharyngeal SCC, which emphasizes the prognostic importance of CLNM.

With respect to the time of appearance, most studies corroborate that CLNM mainly happens within two years postoperatively ${ }^{[17-20]}$ For instance, González-García et al. ${ }^{[20]}$ in a series of 203 patients with oral squamous cell carcinoma of the tongue, with especial consideration in excluding those cases involving the midline or at a distance less than $1 \mathrm{~cm}$, reported CLNM occurring within the first 2 years after surgery in $89.9 \%$ of the affected patients. Therefore, special effort should be paid early detecting nodal relapse in the cervical región,while a careful follow-up is mandatory during this period of time.

\section{PREDICTIVE FACTORS}

Several clinical and pathological factors have been proposed 
to be correlated with the risk of contralateral lymph node metastasis as well as with patient survival. We consider it important to analyze these factors. It is currently unclear whether CLNM are underestimated in OSCC patients at initial presentation. Therefore, correct identification of risk factors associated with CLNM is paramount to improve the clinical outcome of this patient group, especially because ultrasound diagnostic imaging and computed tomography scannings are not sensitive enough to sufficiently detect occult disease. Prediction of tumors at high risk for contralateral involvement may determine a better therapeutic management of the contralateral neck and may improve OSCC prognosis [Table 1].

\section{Tumor location}

One of the factors that has been speculated as a determinant prognosticator for contralateral metastases is tumor location, although there is not a clear consensus about which location is of higher risk for cross-metastases.

The importance of tumor midline involvement had been already exposed by Martin et al. ${ }^{[21]}$ Risk increased to $16 \%$ in cases with tumors crossing the midline by less than $1 \mathrm{~cm}$ and reached $46 \%$ in those where the crossing was of more than $1 \mathrm{~cm}$. In the same way, Koo et al ${ }^{[8]}$ also demonstrated that the rate of contralateral occult neck metastasis was significantly higher in cases in which the primary lesion showed extension across the midline, compared with early-stage or unilateral lesions. In a series including 513 consecutive cases, Kowalski et al..$^{[6]}$ testified that the risks of CLNM were significantly higher in cases of tumors extending to $1 \mathrm{~cm}$ or less of the midline or crossing such medial margin (relative risk from 2.8 to 12.7$)$. In the study of Kurita et al. ${ }^{[5]}$ patients with tumors showing radiological evidence of extension crossing the midline were at a higher risk for CLNM (53.8\%) than patients without an extension crossing the midline (10.3\%).

In relation to the location of the primary tumor, a higher risk for CLNM in patients with tumors of the floor of the mouth and the anterior third of the tongue in detriment of the retromolar region or the lateral gum has been reported. ${ }^{[6]}$ Cross-drainage in the oral tongue and floor of mouth cancer is common, thereby placing both sides of the neck at risk for nodal metastases, as reported in the study by Mukherji et al.$^{[10]}$ Califano et al. ${ }^{[22]}$ found a higher rate of contralateral involvement in the base of the tongue even in early tumors than in the body and the tip of the tongue and recommended prophylactic bilateral neck dissection in all tongue base carcinomas. The data of Olzowy et al. ${ }^{[23]}$ also showed that tumors of the base of tongue had a higher risk of contralateral metastases than that of tumors of the tonsillar fossa. Moreover, although not statistically significant, tumors of the soft palate and the pharyngeal walls also seemed to have a higher risk of CLNM. Capote-Moreno et al. ${ }^{[7]}$ observed a higher tendency for contralateral metastases in tumors located in the tongue base (31.4\%) and the floor of the mouth (11\%), with a lower frequency in the mobile tongue (7.2\%) and the oropharynx (6.3\%). However, in the study of Kurita et al. ${ }^{[5]}$ the incidence of CLNM was higher in cases of lower gum carcinoma (25\%) than in those with mobile tongue carcinoma (15.4\%). They suggested that the direction of tumor invasion is a more important factor for CLNM than the original tumor location in patients with

Table 1: Chart review of the main articles that analyze risk factors for CLNM

\begin{tabular}{|c|c|c|c|c|c|c|c|}
\hline Study & Year & Number & $\begin{array}{c}\text { Mean age } \\
\text { (years) }\end{array}$ & Male:female & $\begin{array}{l}\text { Follow-up } \\
\text { (months) }\end{array}$ & $\begin{array}{c}\text { CLNM } \\
\text { (number of patients) }\end{array}$ & Predictive factors \\
\hline Kowalski et al. ${ }^{[6]}$ & 1999 & 513 & 56.4 & $437: 76$ & - & 38 & $\begin{array}{l}\text { TNM stage and ipsilateral } \\
\text { metastases }\end{array}$ \\
\hline Kurita et al. ${ }^{[5]}$ & 2004 & 126 & 66 & $74: 55$ & 21 & 19 & $\begin{array}{l}\text { T-stage, ipsilateral metastases, } \\
\text { and histo-pathologic grading }\end{array}$ \\
\hline Koo et al..$^{[8]}$ & 2006 & 66 & 53 & $52: 14$ & 44 & 7 & $\begin{array}{l}\text { T-stage and ipsilateral } \\
\text { metastases }\end{array}$ \\
\hline $\begin{array}{l}\text { González-García } \\
\text { et al. }{ }^{[20]}\end{array}$ & 2007 & 203 & 59 & $72: 28$ & 71 & 9 & $\begin{array}{l}\text { Histo-pathologic grading and } \\
\text { peritumoural inflammation }\end{array}$ \\
\hline $\begin{array}{l}\text { González-García } \\
\text { et al. }{ }^{[12]}\end{array}$ & 2008 & 315 & 60 & $222: 93$ & $>5$ years & 18 & $\begin{array}{l}\text { TNM stage, histopathologic } \\
\text { grading, surgical margins, } \\
\text { ipsilateral neck dissection and } \\
\text { perineural invasion }\end{array}$ \\
\hline Liao et al..$^{[31]}$ & 2009 & 913 & 49 & $852: 61$ & $>24$ & 55 & $\begin{array}{c}\text { ECS, tumor location, ipsilateral } \\
\text { metastases and histo- } \\
\text { pathological grading }\end{array}$ \\
\hline $\begin{array}{l}\text { Capote-Moreno } \\
\text { et al. }{ }^{[7]}\end{array}$ & 2010 & 402 & 59 & 293:109 & $>12$ & 20 & $\begin{array}{c}\text { ECS, tumor location, ipsilateral } \\
\text { metastases and histo- } \\
\text { pathological grading }\end{array}$ \\
\hline Olzowy et al. ${ }^{[23]}$ & 2011 & 352 & 56.8 & $274: 78$ & - & 75 & $\begin{array}{l}\text { Tumor location, T-stage and } \\
\text { ipsilateral metastases }\end{array}$ \\
\hline Lin et al. ${ }^{[38]}$ & 2012 & 683 & $>50$ & $624: 59$ & - & $36 / 676$ & $\begin{array}{l}\text { Tumor location and histo- } \\
\text { pathologic grading }\end{array}$ \\
\hline Feng et al. ${ }^{[13]}$ & 2014 & 1,482 & 60 & $822: 66$ & $>5$ years & $35 / 844$ & ECS \\
\hline Habib et al. ${ }^{[33]}$ & 2016 & 481 & 64 & $288: 193$ & 160 & 14 & $\begin{array}{l}\text { Ipsilateral metastases and } \\
\text { histo-pathologic grading }\end{array}$ \\
\hline
\end{tabular}


carcinoma that has originated laterally in the oral cavity.

\section{Tumor size}

The literature reports a strong correlation between the size of the primary and the risk of CLNM. ${ }^{[24-28]} \mathrm{A}$ significant correlation between the T-stage and the occurrence of CLNM was observed by Kurita et al. $\cdot^{[5]}$ In this study, the incidence of CLNM for the T4 tumor (31.4\%) was relatively high compared to that for the T1 $(0 \%)$ as well as the T2 $(12.2 \%)$ and T3 tumor (11.8\%). In addition, CLNM in patients with the T2 and T3 tumor occurred only in cases of the mobile tongue, but not in other sites. Excluding cases of the tongue SCC, CLNM was unlikely in patients with T1 to T3 oral carcinoma that had arisen in the unilateral side. In a retrospective analysis of 66 patients with cancer of the oral cavity at N0-2 stage, Koo et al..$^{[8]}$ showed that the rate of contralateral occult metastasis was $8 \%$ for $\mathrm{T} 2,25 \%$ for $\mathrm{T} 3$, and $18 \%$ for $\mathrm{T} 4$, whereas no metastasis was observed in the $\mathrm{T} 1$ cases.

\section{Tumor thickness}

Tumor thickness has been recognized as an histological prognostic factor of local recurrence, cervical nodal metastasis, and survival. Bier-Laning et al. ${ }^{[9]}$ found an approximately $5 \%$ increased risk of CLNM for every $1-\mathrm{mm}$ increase in tumor thickness. They did not found cases of CLNM when the primary tumor had a thickness less than $3.75 \mathrm{~mm}$. So, they recomended that consideration should be given to observation of the contralateral neck for tumors less than $3.75 \mathrm{~mm}$, neck dissection to the contralateral neck for tumors more than $3.75 \mathrm{~mm}$ thick, and treatment of the contralateral neck with surgery and/ or radiation therapy if the tumor is more than $9.5 \mathrm{~mm}$ thick. This is compatible with the findings of others, in which the risk of ipsilateral nodal metastasis is increased in tumors thicker than $4-5 \mathrm{~mm} .{ }^{[29,30]}$ Other authors, as González-García et al. ${ }^{[12]}$ failed to show tumoral thickness greater than $2 \mathrm{~mm}$ as predictive for CLNM, which could be attributable to the insufficient sample size where $7.1 \%$ of the patients with tumor thickness greater than $2 \mathrm{~mm}$ developed CLNM in comparison with $0 \%$ of the patients with tumor thickness less than $2 \mathrm{~mm}$.

\section{Infiltration of the cervical lymph nodes}

In relation to cervical affectation, ipsilateral lymph neck node metastasis has been referred to as a significant predictor in assessing the risk to the contralateral neck. According to the statistical results of Kurita et al. ${ }^{[5]}$ no CLNM occurred in patients without ipsilateral lymph node metastasis. In addition, the incidence of CLNM was higher in patients with multinode involvement (50\%) than in those with single node involvement (26.1\%). The study reported by Capote-Moreno et al. ${ }^{[7]}$ supported these results, in which $21.6 \%$ of the cases with positive homolateral nodes showed positive CLNM whereas contralateral disease developed in only $6.4 \%$ of the cases with negative homolateral nodes. This prognostic variable, together with tumor extension across the midline, was the most important risk factor in the logistic regression analysis performed in this report. Other studies have also shown a significant correlation between the presence of ipsilateral and CLNM. ${ }^{[6,8]}$ In the study of Olzowy et al..$^{[23]}$ patients with two or more ipsilateral neck metastases showed significantly more bilateral metastases compared with patients with fewer than two positive ipsilateral lymph nodes.

In contrast to these previous studies, González-García et al. ${ }^{[20]}$ did not found an association between the presence of clinical and pathological positive node status on the ipsilateral side of the neck and a higher incidence of contralateral cervical metastasis in SCC of the lateral side of the tongue.

\section{Extracapsular spread}

Transcapsular infiltration of lymph node metastases is another important prognostic factor that, although it can be found in smaller lymph nodes, is generally associated with lymph nodes with a diameter of more than $2 \mathrm{~cm}$. In a retrospective study performed by Feng et al., ${ }^{[13]}$ they demonstrated that extracapsular spread (ECS) status was correlated with 5-year CLNM. In a series of 913 patients, Liao et al..$^{[31]}$ also showed that the 5-year CLNM rate was significantly higher in patients with ECS (39\%) than in those without $(12 \%)$. Furthermore, the 5 -year overall survival was $48 \%$ in patients without ECS, whereas it dropped to $16 \%$ in those with ECS.

However, other authors such as Koo et al. ${ }^{[8]}$ did not find a statistical assocciation between ECS and the ocurrence of CLNM.

\section{Clinical tumor node metastasis stage}

It has been reported that patients with advanced tumors are at a higher risk for CLNM in OSCC ${ }^{[5,6,12]}$ In the multivariate analysis performed by Kowalski et al., ${ }^{\left[{ }^{[6]}\right.}$ it became clear that the risk of CLNM for patients with clinical stage (CS) I and II tumors not involving the floor of the mouth was low, even though it crossed midline $(<1 \mathrm{~cm})$. On the other side, CS IV tumors that were less than $1 \mathrm{~cm}$ away from midline had a high risk of metastasis, independent of tumor original site. Frequency of such metastases was $33 \%$ for stage T4, $15 \%$ for CS III and $32 \%$ for CS IV. Risk of contralateral metastases was over $20 \%$ in stage T1-3 N2a-3 and T4 N0-3 M0 tumors. González-García et al. ${ }^{[12]}$ found in their series that $6.7 \%$ of patients with staging IV in the tumor node metastasis (TNM) classification developed CLNM, whereas only $2.6 \%$ of patients with TNM staging I showed CLNM.

\section{Surgical margins}

In relation to surgical resection, the absence of wide enough margins in the excised primary tumor has been reported to be a predictor for CLNM. Particularly, the presence of $1 \mathrm{~cm}$ or more of non-affected tissue around the tumor was considered adequate, in contrast to 
specimens with less than $1 \mathrm{~cm}$ of non-affected tissue around the tumor. Illustratively, only $4 \%$ of patients in the first group developed CLNM in contrast to $11.6 \%$ of patients in the last group. ${ }^{[12]}$ Nason et al. ${ }^{[32]}$ found that each 1-mm increase in clear surgical margin decreased the risk of death at 5 years by $8 \%$. Other authors have also demonstrated that surgical margins had a statistical association with a higher risk of CLNM developing. ${ }^{[7]}$

\section{Grade of histological differentiation}

Histopathological grading is also an important predictive factor for the occurrence of CLNM in head and neck SCC. For Kurita et al. ${ }^{[5]}$ the risk for CLNM increased as the degree of histopathological grading advanced. In another study, González-García et al. ${ }^{[12]}$ also demonstrated a statistically significant association between histological grading and the appearance of CLNM and found that $13.5 \%$ of the patients with poor-differentiated SCC developed CLNM, in comparison with $5.2 \%$ of patients with well-differentiated tumors. Other authors also have identified poor tumour differentiation as a significant predictor. $^{[5,20,31,33]}$

\section{Tumor satellite distance}

Tumor satellites can be defined as separate islands of tumor cells at the tumor and nontumor interface. Tumor satellite distance (TSD) is the distance from the main tumor to the most distant tumor satellite and reflects the spreading ability of tumor satellites. In the literature, microsatellite tumor spreading was reported to reach as far as $1.8 \mathrm{~cm}^{[34]}$ Yang et al. ${ }^{[35]}$ reported that TSD is significantly associated with the survival of patients with tongue cancer in areas of endemic betel nut consumption. In addition, increased TSD is associated with a higher incidence of local recurrence, shorter intervals to neck recurrence, and a higher tendency to contralateral or bilateral neck metastasis.

\section{Perineural and lymphovascular invasion}

Perineural infiltration of the primary tumor has been shown to be highly predictive for CLNM, as it was illustrated in the series of González-García et al. ${ }^{[12]}$ by the appearance of pathologic contralateral lymph neck nodes in $17.02 \%$ of patients with perineural infiltration, in comparison with $4.1 \%$ of those patients without perineural involvement. In the study of Capote-Moreno et al., ${ }^{[7]}$ perineural invasion also turned out to be arelevant factor for contralateral metastases. Kowalski et al. ${ }^{[6]}$ suggested the presence of lymphovascular involvement, as well as of perineural infiltration, were significantly associated to higher rates of risk of CLNM in OSCC.

\section{Peritumoral inflammation}

A statistically significant association between the absence of peritumoral inflammation and the appearance of CLNM has been observed. A possible explanation for this association could be that a low host immunological response around the primary tumour could allow easier dissemination of cancer cells through lymphatic drainage. ${ }^{[20]}$

\section{Local-regional recurrence}

Local recurrence has been defined as an independent risk factor for CLNM in the study of Liao et al. ${ }^{[31]}$ Specifically, the percentage of CLNM was $18 \%(17 / 132)$ in patients with $\mathrm{LR}$, and 5\% (38/781) in those without.

\section{TREATMENT OPTIONS}

The possibility of occult CLNM in the OSCC requires a challenging decision: whether the contralateral neck should be electively treated or not. No consensus has been reached on the need for contralateral neck dissection (CND) or radiotherapy. Implications of such treatment on the contralateral side include the advantage of treating subclinical disease on the one hand, but on the other hand, because these cases have a poor prognosis, treatment may lead to a significant increase in morbidity and even mortality without improvement.

\section{Neck dissection}

Appropriate management of cervical lymph nodes is an important aspect of the treatment of patients with OSCC. Although elective treatment of the contralateral neck is accepted for oral cancers approaching or crossing the midline, this is not routinely performed in lateralized cases. Unfortunately, even with the use of elective CND for ipsilateral tumors crossing the midline, approximately one-third of neck lymph node recurrences occur at the contralateral site. So, it is unclear whether the use of elective CND may reduce incidence of contralateral neck recurrences in this patient group.

Various studies have failed to show a benefit in the survival rate from elective treatment of the contralateral neck. ${ }^{[11,13,36]}$ The reduced survival in some patients with OSCC appears to reflect aggressive disease biology with regional and/or distant failure in spite of salvage therapy, suggesting that elective treatment of the contralateral neck is unlikely to improve their prognosis. So, some surgeons advocate an observation-only policy for the contralateral neck. For example, Lim et al. ${ }^{[11]}$ examined 54 patients with early stage SCC of the oral tongue. The goal of this study was to determine if there was an outcome difference between patients who underwent observation of the contralateral neck (29 patients) versus the 25 patients who underwent bilateral elective neck dissection (END). Notably, 7 patients in the "observation" group underwent radiation therapy that included the contralateral neck. The incidence of recurrence at any site in this study was $17 / 54$ (31\%), with no recurrences in the contralateral neck. There was only 1 of 25 (4\%) CNDs that showed occult malignancy. There was no significant difference in the disease-free survival between those 
who underwent observation of the contralateral neck and those who underwent contralateral END, even when those in the observation group who received radiation therapy were excluded.

Although the reason for these findings is unclear, it has been suggested that END, in conjunction with primary tumor resection, may predispose patients to aberrant migration of intransit carcinomatous cells to the opposite side of the neck. ${ }^{[12]}$ Chow et al. ${ }^{[28]}$ failed to show bilateral neck dissections reduced the contralateral neck relapse by statistical testing. Remarkably, only 1 of the 12 patients undergoing bilateral neck dissection as part of their definitive treatment developed contralateral nodal recurrence. In contrast, 8 of the 46 patients undergoing only ipsilateral neck dissection developed contralateral or bilateral nodal recurrence. In the same way, for González-García et al. ${ }^{[12]}$ unilateral cervical dissection was predictive for CLNM. In fact, only $1.8 \%$ of the patients that primarily underwent bilateral neck dissection developed CLNM, in comparison with $7.4 \%$ of those patients undergoing unilateral neck dissection. Remarkably, only 2 of 64 patients undergoing bilateral neck dissectionas definitive treatment developed CLNM. In contrast, 14 of 149 patients undergoing ipsilateral neck dissection developed CLNM. However, despite these results, they stated that the low reported incidence of CLNM and the added morbidity supported recommendation for bilateral neck dissection in selected patients with tumors primarily arising in the midline.

Lanzer et al. ${ }^{[4]}$ did neither show a statistical benefit of elective CND in patients with contralateral clinically negative neck. Neither locoregional recurrence-free survival nor overall survival rates differed.

In another study, performed by Liao et al., ${ }^{[3] \mid}$ the independent risk factors for the 5-year CLNM rate were poor differentiation, perineural invasion, and level IV/V lymph node metastases. A prognostic scoring system was thus formulated by summing up the three significant factors identified by multivariate analysis. In order to reduce the incidence of CLNM, CND and adjuvant therapy were recommended in high-risk patients with tongue cancer [score 2-3, 5-year nonrenal clearance rate (CLNR) $40 \%$ ]. In the intermediate-risk group (score 1, 5-year CLNR $15 \%)$, neck ultrasound examinations were recommended every 3 months until 24 months postoperatively. Observation should be considered sufficient for low-risk patients (score 0, 5-year CLNR 3\%).

In a recent study by Fan et al., ${ }^{[37]}$ all indications for contralateral END in oropharyngeal SCC were summarised as leading to: (1) tumours crossing the midline; (2) advanced staging (cT34); (3) primary tumour more than $3.75 \mathrm{~mm}$ thick; (4) multiple ipsilateral node involvement; and (5) tumours arising in the base of the tongue and floor of the mouth.

The location of the primary tumor plays an important role in other studies. The carcinoma of the base of tongue seems to have a high propensity to produce bilateral neck metastases. For Olzowy et al., ${ }^{[23]}$ in the case of involvement of the base of tongue, the neck should be operated on bilaterally, independent of $\mathrm{T}$ classification of the primary. In carcinomas of the soft palate greater than $\mathrm{T} 1$, bilateral neck dissection should also be recommended because of a high frequency of bilateral metastases. For Lin et al. ${ }^{|38|}$ prophylactic CND is suggested for primary oral tumors with mouth floor invasion or midline crossing, or at advanced tumor stage ( $>$ T3). This recommendation is not supported by most authors.

In summary, despite facing a high number of occult lymph node metastasis in the ipsilateral and contralateral neck in oral cancer, the locoregional recurrence rate seems to be low. Surgeons should take into account the detailed and individual study of risks and potential benefits of elective neck treatment for contralateral N0 neck while considering the small percentage of patients with oral carcinoma that finally develop CLNM.

\section{Adjuvant radiotherapy}

The alternative to the bilateral neck dissection is radiotherapy (RT) of the contralateral neck in the case of a relevant risk of bilateral metastases, particularly in patients receiving planned adjuvant RT postoperatively. In this way, Capote-Moreno et al..$^{[7]}$ recommended bilateral treatment of the neck with surgery or RT in patients with several risk factors. On the other hand, Koo et al..$^{[8]}$ showed that the patients who received adjuvant RT had a lower locoregional control and survival rate compared with those who did not receive adjuvant RT. However, this was attributed to the fact that the patients who received adjuvant RT were those who had an advanced-stage disease or worse prognosis, which would have affected the locoregional control and survival rate. Finally, they suggested elective contralateral neck management with surgery or RT in the treatment of OSCC patients with ipsilateral node metastasis and/or those with tumors either greater than stage T3 or crossing the midline.

The results of the Radiation Therapy Oncology Group and European Organization for Research and Treatment of Cancer trials have provided evidence that in patients with head and neck cancer surgery plus concomitant chemoradiation (CCRT) had a better impact on clinical outcome compared with surgery plus RT. ${ }^{[39,40]}$ The benefits of CCRT were especially evident in head and neck cancer patients with positive margins and ECS. ${ }^{[40]}$ In the study performed by Feng et al., ${ }^{113]}$ postoperative CCRT compared with surgery alone improved the 5-year disease-specific survival in these high-risk patients but did not decrease the 5-year CLNM rate. However, it is important to take in mind that the use of CCRT in the adjuvant setting, which is highly toxic, may cause immunosuppression. ${ }^{[41]}$ For these authors, whether high-risk patients benefit from 
contralateral neck dissection plus adjuvant CCRT can only be answered in a prospective trial.

To come to conclusions, when RT is employed as the elective treatment modality, the threshold for treating the contralateral neck is low, taking in mind the difficulty of future treatment in cases of recurrence, and the relative low additional morbidity associated with the therapy. Thus, in patients at a moderate-high risk of developing CLNM, contralateral neck should be included in the radiation field.

\section{CONCLUSION}

The OSCC presents a variable incidence of CLNM, reported between $0.9 \%$ to $36 \%$ and it has been widely accepted that CLNM dramatically reduce long-term survival and prognosis. Several predictive factors have been proposed to be correlated with the risk of contralateral lymph node metastasis, such as tumor location, size or thickness, ipsilateral lymph node metástasis, ECS, TNM stage, surgical margins, grade of hystological differentiation, tumor satellite distance, perineural and lymphovascular invasion, peritumoral inflammation and local recurrence.

It is important for clinicians to pay careful attention to these prognostic variables that must be globally considered for each individual case. Surgeons should take into account the detailed and individual study of risks and potential benefits of elective neck treatment for contralateral NO neck while considering a small percentage of patients with oral carcinoma that finally develop CLNM.

\section{Financial support and sponsorship Nil.}

\section{Conflicts of interest}

There are no conflicts of interest.

\section{REFERENCES}

I. Fasunla AJ, Greene BH,Timmesfeld N,Wiegand S, Werner JA, Sesterhenn AM. A meta-analysis of the randomized controlled trials on elective neck dissection versus therapeutic neck dissection in oral cavity cancers with clinically node-negative neck. Oral Oncol 20 I I;47:320-4.

2. Campana JP, Meyers AD. The surgical management of oral cancer. Otolaryngol Clin North Am 2006;39:33I-48.

3. Jalisi S. Management of the clinically negative neck in early squamous cell carcinoma of the oral cavity. Otolaryngol Clin North Am 2005;38:37-46.

4. Lanzer M, Zemann W, Lubbers TH, Kruse A, Reinisch S. Do patients with oral and oropharyngeal squamous cell carcinoma benefit from elective contralateral neck dissection? A long-term analysis. Head Neck Oncol 2012;4:70-5.

5. Kurita H, Koike T, Narikawa J, Sakai H, Nakatsuka A, Uehara S, Kobayashi $\mathrm{H}$, Kurashina K. Clinical predictors for contralateral neck lymph node metastasis from unilateral squamous cell carcinoma in the oral cavity. Oral Oncol 2004;40:898-903.

6. Kowalski LP, Bagietto R, Lara JR, Santos RL, Tagawa EK, Santos IR. Factors influencing contralateral lymph node metastasis from oral carcinoma. Head Neck 1999;21:104-10.
7. Capote-Moreno A, Naval L, Muñoz-Guerra MF, Sastre J, RodríguezCampo FJ. Prognostic factors in uencing contralateral neck lymph node metastases in oral and oropharyngeal carcinoma. J Oral Maxillofac Surg 2010;68:268-75.

8. Koo BS, Lim YC, Lee JS, Choi EC. Management of contralateral NO neck in oral cavity squamous cell carcinoma. Head Neck 2006;28:896-90I.

9. Bier-Laning CM, Durazo-Arvizu R, Muzaffar K, Petruzzelli GJ.Primary tumor thickness as a risk factor for contralateral cervical metastases in TI/T2 oral tongue squamous cell carcinoma. Laryngoscope 2009; | 9:883-8.

10. Mukherii SK,Armao D, JoshiVM. Cervical nodal metastases in squamous cell carcinoma of the head and neck: what to expect. Head Neck 2001;23:995-1005.

II. Lim YC, Lee JS, Koo BS, Kim SH, Kim YH, Choi EC. Treatment of contralateral NO neck in early squamous cell carcinoma of the oral tongue: elective neck dissection vs. observation. Laryngoscope 2006; I | 6:46I-5

12. González-García R, Naval-Gías L, Rodríguez-Campo FJ, Sastre-Pérez J, Muñoz-Guerra MF, Gil-Díez Usandizaga JL. Contralateral lymph neck node metastasis of squamous cell carcinoma of the oral cavity: a retrospective analytic study in 315 patients. J Oral Maxillofac Surg 2008:66:1390-8.

13. Feng Z, Niu LX, Yuan Y, Peng X, Guo CB. Risk factors and treatment of contralateral neck recurrence for unilateral oral squamous cell carcinoma: a retrospective study of 1482 cases. Oral Oncology 2014;50:1081-8.

14. Huang SF, Wei FC, Liao CT, Wang HM, Lin CY, Lo S, Huang JJ, Chen IH, Kang $\mathrm{CJ}$, Chien $\mathrm{HT}$, Chen $\mathrm{HH}$. Risk stratification in oral cavity squamous cell carcinoma by preoperative CRP and SCC antigen levels. Ann Surg Oncol 2012;19:3856-64.

15. Shingaki S, Takada M, Sasai K, Bibi R, Kobayashi T, Nomura T, Saito C. Impact of lymph node metastasis on the pattern of failure and survival in oral carcinomas. Am J Surg 2003; 185:278-84.

16. Greenberg JS, El Naggar AK, Mo V, Roberts D, Myers JN. Disparity in pathologic and clinical lymph node staging in oral tongue carcinoma. Cancer 2003;98:508-15.

17. Jang WI, Wu HG, Park Cl, Kim KH, Sung MW, Kim MJ, Choung PH, Lee $\mathrm{JH}$, Chao JY. Treatment of patients with clinically lymph node-negative squamous cell carcinoma of the oral cavity.Jpn J Clin Oncol 2008;38:395401.

18. Vandenbrouck C, Sancho-Garnier H, Chassagne D, Saravane D, Cachin Y, Micheau C. Elective versus therapeutic radical neck dissection in epidermoid carcinoma of the oral cavity: results of a randomized clinical trial. Cancer 1980;46:386-90.

19. Snow GB, Annyas AA, van Slooten EA, Bartelink H, Hart AA. Prognostic factors of neck node metastasis. Clin Otolaryngol Allied Sci 1982;7: 185-92.

20. González-García R, Naval-Gías L, Sastre-Pérez J, Rodriguez-Campo FJ, Muñoz-Guerra MF, Gil-Diez Usandizaga JL, Diaz-Gonzalez FJ. Contralateral lymph neck node metastasis of primary squamous cell carcinoma of the tongue: a retrospective analytic study of 203 patients. Int J Oral Maxillofac Surg 2007;36:507-13.

21. Martin H, Del Valle B, Ehrlich H, Cahan WG. Neck dissection. Cancer 1951;4:44I-99.

22. Califano L, Zupi A, Mangone GM, Longo F, Coscia G, Piombino P. Surgical management of the neck in squamous cell carcinoma of the tongue. $\mathrm{Br} J$ Oral Maxillofac Surg 1999;37:320-3.

23. Olzowy B,TsalemchukY, Schotten KJ, Reichel O, Harréus U. Frequency of bilateral cervical metastases in oropharyngeal squamous cell carcinoma: a retrospective analysis of 352 cases after bilateral neck dissection. Head Neck 20I I;33:239-43.

24. Woolgar JA, Rogers S, West CR, Errington RD, Brown JS, Vaughan ED. Survival and patterns of recurrence in 200 oral cancer patients treated by radical surgery and neck dissection. Oral Oncol 1999;35:257-65.

25. Gallo O, Fini-Storchi I, Napolitano L. Treatment of the contralateral negative neck in supraglottic cancer patients with unilateral node metastases (NI-3). Head Neck 2000;22:386-92.

26. Woolgar JA. The topography of cervical lymph node metastases revisited: the histological findings in 526 sides of neck dissection from 439 previously untreated patients. Int J Oral Maxillofac Surg 2007;36:2 I9-25.

27. Lim YC, Lee SY, Lim JY, Lim JY, Shin HA, Lee JS, Koo BS, Kim SH, Choi EC. Management of contralateral NO neck in tonsillar squamous cell carcinoma. Laryngoscope 2005; I 15:1672-5.

28. Chow TL, Chow TK, Chan TT, Yu NF, Fung SC, Lam SH. Contralateral 
neck recurrence of squamous cell carcinoma of oral cavity and oropharynx. J Oral Maxillofac Surg 2004;62:1225-8.

29. Hayashi T, Ito J, Taira S, Katsura K. The relationship of primary tumor thickness in carcinoma of the tongue to subsequent lymph node metastasis. Dentomaxillofac Radiol 2001;30:242-5.

30. Kurokawa H, Yamashita Y, Takeda S, Zhang M, Fukuyama H, Takahashi T. Risk factors for late cervical lymph node metastases in patients with stage I or II carcinoma of the tongue. Head Neck 2002;24:73 I-6.

3I. Liao CT, Huang SF, Chen IH, Chang JT, Wang HM, Ng SH, Hsueh C, Lee LY, Lin CH, Cheng AJ, Yen TC. Risk stratification of patients with oral cavity squamous cell carcinoma and contralateral neck recurrence following radical surgery. Ann Surg Oncol 2009; 16:159-70.

32. Nason RW, Binahmed A, Pathak KA,Abdoh AA, Sándor GK. What is the adequate margin of surgical resection in oral cancer? Oral Surg Oral Med Oral Pathol Oral Radiol Endod 2009; 107:625-9.

33. Habib M, Murgasen J, Gao K,Ashford B, Shannon K, Ebrahimi A, Clark JR. Contralalteral neck failure in lateralized oral squamous cell carcinoma. ANZJ Surg 2016;86:188-92.

34. Brandwein-Gensler M, Teixeira MS, Lewis CM, Lee B, Rolnitzky L, Hille J], Genden E, Urken ML, Wang BY. Oral squamous cell carcinoma: histologic risk assessment, but not margin status, is strongly predictive of local disease-free and overall survival. Am J Surg Pathol 2005;29: I 67-78.

35. Yang TL, Wang CP, Ko JY, Lin CF, Lou PJ. Association of tumor satellite distance with prognosis and contralateral neck recurrence of tongue squamous cell carcinoma. Head Neck 2008;30:63I-8.

36. Donaduzzi LC, De-Conto F, Kuze LS, Rovani G, Flores ME, Pasqualotti
A. Occurrence of contralateral lymph neck node metastasis in patients with squamous cell carcinoma of the oral cavity. J Clin Exp Dent 20|4;6:209-13.

37. Fan S, Tang QL, Lin YJ, Chen WL, Li JS, Huang ZQ, Yang ZH, Wang YY, Zhang DM, Wang HJ, Dias-Ribeiro E, Cai Q, Wang L. A review of clinical and histological parameters associated with contralateral neck metastases in oral squamous cell carcinoma. Int J Oral Sci 20 I I;3: I80-91.

38. Lin TC, Tsou YA, Bau DT,Tsai MH. Factors influencing contralateral neck metastasis in oral squamous cell carcinoma. Formosan J Surg 20I 2;45:83-7.

39. Cooper JS, Pajak TF, Forastiere AA, Jacobs J, Campbell BH, Saxman SB, Kish JA, Kim HE, Cmelak AJ, Rotman M, Machtay M, Ensley JF, Chao KS, Schultz C], Lee N, Fu KK; Radiation Therapy Oncology Group 950I/ Intergroup. Postoperative concurrent radiotherapy and chemotherapy for high-risk squamous cell carcinoma of the head and neck. $N$ Engl J Med 2004;350: 1937-44

40. Bernier J, Domenge C, Ozsahin M, Matuszewska K, Lefèbvre JL, Greiner RH, Giralt J, Maingon P, Rolland F, Bolla M, Cognetti F, Bourhis J, Kirkpatrick A, van Glabbeke M; European Organization for Research and Treatment of Cancer Trial 2293I. Postoperative irradiation with or without concomitant chemotherapy for locally advanced head and neck cancer. N Engl J Med 2004;350:1945-52.

4I. Bernier J, Cooper JS, Pajak TF, van Glabbeke M, Bourhis J, Forastiere A, Ozsahin EM, Jacobs JR, Jassem J, Ang KK, Lefèbvre JL. Defining risk levels in locally advanced head and neck cancers: a comparative analysis of concurrent postoperative radiation plus chemotherapy trials of the EORTC and RTOG. Head Neck 2005;27:843-50. 